\title{
Material Selection of the Exploration to the Composition Teaching Strategy of Life Value in Senior High School Chinese
}

\author{
Xiang $L v^{1, a^{*}}$ \\ ${ }^{1}$ Personnel Department, China West Normal University, China \\ ajuliezhyh@163.com
}

\begin{abstract}
Keywords: Teaching in senior high school; Composition teaching; Life value education; Educational strategies
\end{abstract}

\begin{abstract}
In recent years, adolescents' suicide, homicide and school violence emerge in endless stream and are on the rise. Adolescents' life consciousness is weak and such phenomenon is increasingly prominent. On the basis of those, the author manages to explore the strategies of adolescents' education on life value from the angle of material selection; thus it can inspire them into thinking about and comprehending life, pursuing the life being. As a result, the adolescents pay attention to life, face life and establish the correct value of life and fully live up to the wonderful.

The famous educator named Ye Lan has said, "In a certain sense, education is a kind of social activity which faces human life, through human life and for the improvement of human life's quality. Education is a kind of career which mostly reflects consideration about life in human-rooted society. [1]New curriculum reform has repeatedly stressed that Chinese education should be people-oriented and be about life, to achieve the Chinese language of humanity. The essay teaching, as an important link in whole Chinese teaching, is the main position of students' life value education. Through essay teaching, students learn to look at nature, comprehend life and think about life. In that case, it can promote the students' capacity of perceiving life, revering life and cherishing life. Therefore, essay teaching is a significant way of improve the effectiveness of life value education.
\end{abstract}

Ye Shengtao has said, "Life is like a fountain, the fountain of abundance, like streams, streams naturally lively on the clock."[2] Composition material is from rich social life and students' deep observation and unique emotional experience of life, so the way of writing material should be varied: it can come from real social life, Classical documents, teaching material or abundant network resources.

But for a long time, the examination-oriented education concept has caused that composition teaching is lack of subjectivity, teaching material lack of selection and writing lack of uniqueness. Composition has become a torment for students who have to do that and has formed a embarrassing phenomenon—one cannot make brick without straw. Then composition about Oneself is not true; about family not close; about school not new and about society not deep.[3] As a result, teachers, in essay teaching and training, should help students to accumulate and select writing material; make efforts to give more freedom on students' subject material; guide students to pay more attention to personal emotional world, society, nature and life; widen students' cognitive perspectives; encourage students to take part in life and experience life; lead students to expressing their own real feelings in order to avoid creating feelings for writing.

\section{Material Close to Life, Shortening the Distance of Students' Perceiving Life}

In General High School Chinese Curriculum Standard(Experiment),"expression and communication" describes:"students should learn to observe life from different angles, enrich their own life and emotional experience, have their own feelings and thoughts about nature, society and life. "Without doubt, writing is an activity of expressing inner feelings and self-thinking. If students want to express their life experience by way of writing, they have to enter life and experience life. Only in this way, can words read real and moving. The same as the sense of life, writing for life means writing 
is a expression of life, "in the heart of the smoldering, from the natural disposition." As a carrier and link of students' own real life experience, writing can be an approach of expressing themselves really and pent-up emotion. Therefore, writing material, on the basis of careful observation and profound thinking of present life, inevitably facilitates students to have correct understanding of life and reality and also have reasonable localization in life. Students walk out of the narrow classroom, enter capacious nature, with their own unique vision to observe and experience life, find the beauty and splendor of life and will be motivated their consciousness of cherishing life, which have a significance to develop a sense of life and cultivate their character and personality.

\section{Material from Curriculum Resources, Consolidating Students' Life Sentimental Education}

Chinese context contents have been proved to be classical and famous works, which are composition samples regardless of language expression and thought. Meanwhile, Chinese contexts are the carriers of Chinese traditional excellent culture; the life wisdom and life theme are the treasure-house of Chinese essay material in High School. To be active to explore the educational resource of life value in Chinese contexts in High School benefits strengthening students' life sentimental education.

In Chapter One of Principles of Filial Piety: "my body, including my hair and skin, given by my parents, shouldn't be damaged; this is the essence of filial piety."[5] The basic requirement of filial piety is to cherish one's own life and one should not injure his own body at will. Filial piety culture in Confucian claims that people should show filial respect for their parents and feel grateful to their ancestors, so it is not only to cherish one's own life but also to respect others' lives. Sima Qian in A Letter to Ren a wrote down his feeling of suffering from castration — the pain of feeling in the intestinal transiting. Facing such torture that common people cannot endure, he still vested tenacious spirits to his life and effected transcendence of life___ "with research on combination of heaven and man, through the change of ancient and modern, he has created philosophy of his own." Wang Xizhi in Preface to the Lanting Collection said, "Life and death are matters of great magnitude."Life and death are matters of great magnitude in one's whole life, so it must be cautious to treat with life and death. Meanwhile, he pointed out, "The choices are so widely apart, and the temperaments in terms of quiet or boisterous behaviors are most different. When people are glad of their situations and feel contentment with their temporary gains, they are unaware of the approaching old age." the happiness of life comes from the correct understanding of life. Only people, who love life, cherish time and have an active attitude towards life, are full of happiness. Su Shi in Boating at the Red Cliff exclaimed, "Lamenting our fleeting existence and envying the everlasting Yangtse River", to express regret for short life, warning that we should appreciate life and burst into bloom. Life is so limited and tender; life and death are common things and exist as objective reality. In essay teaching, teachers should show those classical materials which can help students understand the rarity of life and cherish this life, calming in the face of difficulties and hardships in life.

The graceful scenery in My nanny Dayanhe, The moonlight in the lotus pond and Wang Haichaoetc. Makes people relaxed and happy, forgetting to leave on the scoop and also contains authors' keen love and deep attachment to natural fine view. The Love between Children and Parents, The Border Town and Memorial to the Emperor Stating show us the family affection, which is the intense care of life; The peacock Flies Southeast, The deserted Wife of We and The Nape guide readers to experience the eternal charm of sincere love; Bing Xin: Ba Jin, ALetter to Weizhi and Sending Shen Zifu to Jiangdong embody authors' missing and cherishing the friendship. From these materials, students can experience emotion full of variety in the society and recognize that every life is not lonely. Meanwhile, teachers help students to deal with the relationship between man and nature, society and other people and help the students to establish harmonious emotion relationship on kinship, friendship and affections. In that way, students learn to revere life and death, experience happiness and cherish life to a higher degree.

"Man's life quality absolutely depends not only on his knowledge, wisdom and other cognitive factors, but also more on his pursuit and affirmation of the meaning and value of life; man's life 
quality depends on his emotion and attitude, etc. of his self, natural environment and social environment."[6]Teachers give students life education by means of writing material and lead to the influence of life emotion, prompting students to seek what is truly worth pursuing and improving the quality of their lives.

\section{Materials from the Internet, Enriching Students' Life-emotion Experience}

With the arrival of "Internet Plus", internet has permeated all the sides of our life. Colorful and complex network resources have a negative effect on students, such as treating life with indifference, being passive and world-weary and having propensity for violence, but teachers can take good use of network resources which spread positive energy. Chinese teachers should keep pace with the times, learning to select material from abundant network materials and take advantage of multimedia to enrich students' life experience in terms of vision and hearing. Furthermore, students can have a more thought and perception of society and life.

In one writing training__ theme on coloring life, the author displayed the pictures as follows and attached brief words under the pictures.

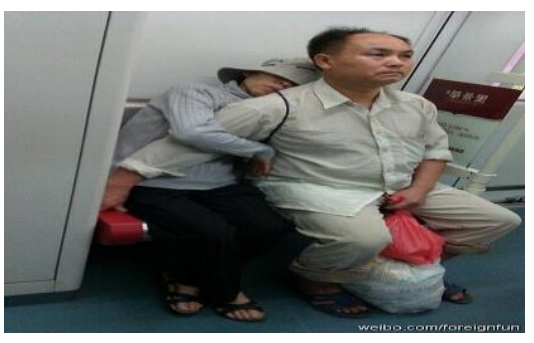

Figure 1.

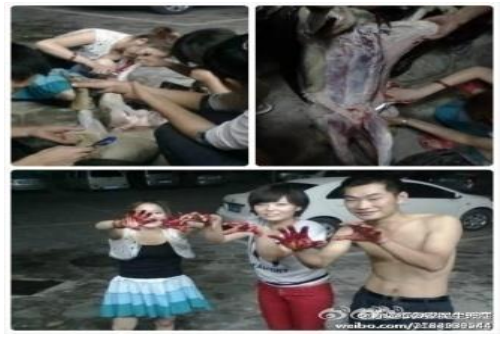

Figure 2.

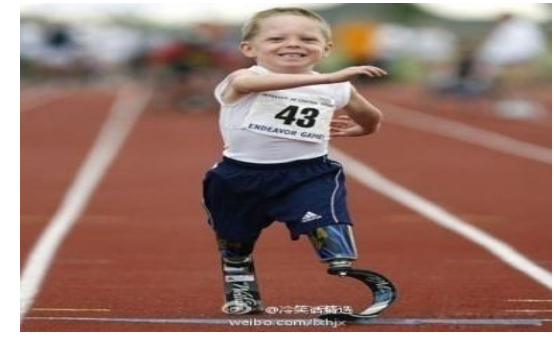

Figure 3.

Fig. 1.There is not romance,but a seat of more than one meters — this is the sweet of love.

Fig. 2.A group of young people take audodyne of skinning puppy alive_ how abnormal their behaviors are.

Fig. 3. Please use your smile to change the world; do not let the world change your smile

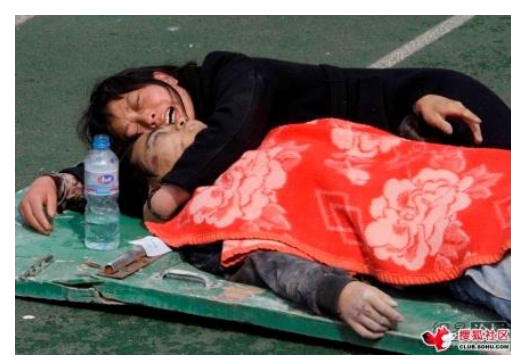

Figure 4.

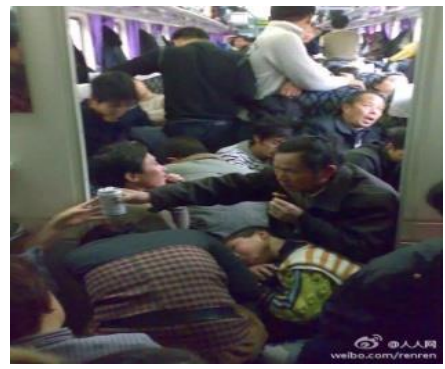

Figure 5.

Fig. 4 Child, your death means two more souls follow you.

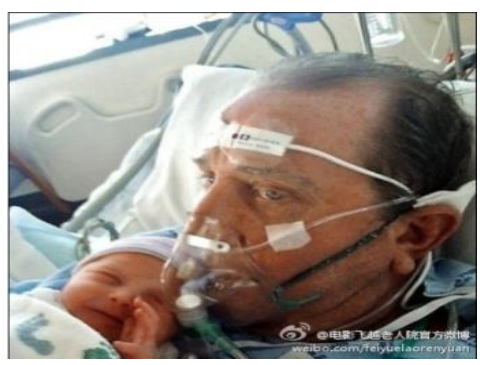

Figure 6.

Fig. 5 To the joy of reunion, the pain of the process means nothing.

Fig. 6 The man has the persistence of life for 45 minutes in order to see the most beautiful smile of his daughters'.

At the sight of these pictures, the author found many students' eyes moist. At that moment, students' thought valve has been unfolded. They knew they cried not for himself but for the calling of life reflecting from the pictures. Because the real example gave a stimulus in sense organ, students 
had been in a exciting state in a short time and their interest had been aroused. Some students said that in the first picture they could sense wordless love__ hold your hand and grow old together with you; some students said they could sense the hate and give their hatred for young people's treating life with indifference in the second picture; some students said that they could sense the strength and love of life in the third picture; some students said they could sense love and responsibility, life not only for oneself in the fourth picture; some students said that they could sense longing for life in sixth picture..."

Then, the author ordered that students be free to express their inspirations and discuss according to groups. In the stage of communication, students' thoughts were stimulated and more students gained new experiences and senses; what's most important was that students gradually understood the significance of life. At last, the author supplemented the complete story in pictures, consolidating the students' sense of life.

Relying on the real examples, students' emotions are real and their attitudes have more impressment feeling. Essay teaching is a communicative site for teachers and students in terms of knowledge, emotion and even life significance. Each essay teaching should be a baptism of life and an awakening of life. "Only if adolescents have requisite responsibility consciousness, they can be full of enterprise and initiative in study and life and go forward in the correct direction. Cultivating students' responsibility means teaching students a significant and valuable life."[8] Respect for life, reverence for life and love of life are not only the materials in essay teaching classes, but the start point and end result of education.

\section{References}

[1] Ye Lan. The connotation of educational life foundation. Shanxi Education. 2004,No6.P1

[2] Ye Shengtao. Ye Shengtao Education Corpus.Vol.2. Beijing: the people's education press.1994. P7.

[3] Yin Xidong. How to step out of dilemmas of ostentation and unconventionality for composition teaching. Chinese Teaching \& Studies. 2004, Vol22. P12-13.

[4] The Ministry of Education of the People's Republic of China. General High School Chinese Curriculum Standard (Experiment). Beijing: The People's Education Press.2003.P9.

[5] Wang Shoukuan. The Interpretation of principles of filial piety. Shanghai: Shanghai ancient books publishing house. 2004. P2.

[6] Yang Wenying. The Research on the life education in the selected text of experimental textbooks of senior High schools of PEP edition (compulsory). Master's Degree Thesis of Northeast Normal University. 2009. P5.

[7] Zhang Su-ling, Ba Zhaocheng, Qin Jingmin. Life Education. Shan Dong: China university of petroleum press.2007. P76.

[8] Ye Shengtao. Ye Shengtao's Set. Beijing: Joint Publishing, 1983.P262.

[9] Wang Li.Reflection on Chinese in China. Beijing: Science and Education Press.1998.P231. 